\title{
A CIC Chloride Channel Homolog and Ornithine-Containing Membrane Lipids of Rhizobium tropici ClAT899 Are Involved in Symbiotic Efficiency and Acid Tolerance
}

\author{
Keilor Rojas-Jiménez, ${ }^{1}$ Christian Sohlenkamp, ${ }^{2}$ Otto Geiger, ${ }^{2}$ Esperanza Martínez-Romero, ${ }^{2}$ \\ Dietrich Werner, ${ }^{1}$ and Pablo Vinuesa ${ }^{1,2}$
}

${ }^{1}$ FB Biologie der Philipps-Universität, FG Zellbiologie und Angewandte Botanik, Karl-von-Frisch-Str., D-35032 Marburg, Germany; ${ }^{2}$ Centro de Ciencias Genómicas, Universidad Nacional Autónoma de México, Cuernavaca, Morelos, México

Submitted 13 March 2005. Accepted 22 June 2005.

\begin{abstract}
Rhizobium tropici CIAT899 is highly tolerant to several environmental stresses and is a good competitor for nodule occupancy of common bean plants in acid soils. Random transposon mutagenesis was performed to identify novel genes of this strain involved in symbiosis and stress tolerance. Here, we present a genetic analysis of the locus disrupted by the Tn5 insertion in mutant 899-PV9, which lead to the discovery of $s y c A$, a homolog of the CIC family of chloride channels and $\mathrm{Cl}^{-} / \mathrm{H}^{+}$exchange transporters. $\mathrm{A}$ nonpolar deletion in this gene caused serious deficiencies in nodule development, nodulation competitiveness, and $\mathrm{N}_{2}$ fixation on Phaseolus vulgaris plants, probably due to its reduced ability to invade plant cells and to form stable symbiosomes, as judged by electron transmission microscopy. A second gene (olsC), found downstream of $s y c A$, is homologous to aspartyl/asparaginyl $\beta$-hydroxylases and modifies two species of ornithine-containing lipids in vivo, presumably by hydroxylation at a still-unknown position. A mutant carrying a nonpolar deletion in ols $C$ is symbiotically defective, whereas overexpressed OlsC in the complemented strain provokes an acid-sensitive phenotype. This is the first report of a CIC homolog being essential for the establishment of a fully developed $\mathrm{N}_{2^{-}}$ fixing root nodule symbiosis and of a putative $\beta$-hydroxylase that modifies ornithine-containing membrane lipids of $R$. tropici CIAT899, which, in turn, are contributing to symbiotic performance and acid tolerance.
\end{abstract}

In order to accomplish a successful symbiotic interaction with legumes, rhizobia have to cope with different stress conditions they encounter in soil, the rhizosphere, and the symbiosome. Soil acidity limits symbiotic $\mathrm{N}_{2}$ fixation and crop productivity in many soils of the tropics and subtropics (Aarons and Graham 1991; Hungria and Vargas 2000; Zahran 1999). It causes nitrogen deficiency in legumes as it inhibits rhizobial growth, root infection, and bacteroid activity (Glenn et al. 1999; Munns et al. 1981). In the rhizosphere, plants secrete $\mathrm{H}^{+}$and organic acids that acidify the soil up to

Corresponding author: P. Vinuesa; Av. Universidad s/n, col. Chamilpa Apdo. 565A; Telephone: +52 777313 1697; Fax +52 777317 5581; Email: vinuesa@ccg.unam.mx

Nucleotide sequence data from this study $(3,761 \mathrm{bp})$ are available from the GenBank database under accession number AY954450. two $\mathrm{pH}$ units below the surrounding bulk soil (Marschner 1995). In addition, the presence of antibacterial molecules and the strong competence between microorganisms for nutrients constitute further stress factors that could constrain nodulation (Jjemba 2001; Walker et al. 2003). Finally, rhizobial bacteroids also face an acidic environment in the peribacteroid space, which has been estimated to be up to two $\mathrm{pH}$ units more acidic than the plant cell cytosol (Udvardi and Day 1997). Bacteroids also face osmotic and oxidative stresses as well as microaerobiosis in the symbiosomes (Day et al. 2001; Nogales et al. 2002). Acid stress is, therefore, a common limiting factor all the way from the soil to the symbiosome, which suggests the existence of different mechanisms of adaptation.

It is well-known that rhizobial species exhibit different levels of tolerance to acidity (Munns et al. 1979; Graham et al. 1982, 1994). However, the genetic and physiological bases of this acid tolerance are still not clear. Two mechanisms related to the acid-tolerance response have been identified in rhizobia and enterobacteria (Foster 1999; Merrell and Camilli 2002; O'Hara and Glenn 1994;). The first involves the synthesis of outer membrane proteins and changes in the structure of lipopolysaccharides, exopolysaccharides, and fatty acids to enhance cell surface stability and to prevent proton permeability (Ballen et al. 1990; Chen et al. 1993a; Reeve et al. 1997). The second mechanism is related to the maintenance of intracellular $\mathrm{pH}$ homeostasis (Chen et al. 1993b). Proton influx in low-pH environments such as that faced by Escherichia coli during gastric tract infection is counteracted in the cytoplasm by decarboxylation of amino acids to consume protons and antiporter activity to remove products (Foster 1999; Merrell and Camilli 2002). Export of positively charged substrates could cause hyperpolarization of the inner membrane; however, this process is prevented by $\mathrm{Cl}^{-} / \mathrm{H}^{+}$exchangers of the $\mathrm{ClC}$ family, which act as electrical shunts (Accardi and Miller 2004; Chen 2005; Iyer et al. 2002;). Additional but yet-unknown mechanisms for acid tolerance might operate in rhizobia.

Rhizobium tropici CIAT899 is highly tolerant to many environmental stresses and particularly to acidity. It is able to grow on media acidified down to $\mathrm{pH} 4.0$, and it is a good competitor for nodule occupancy of Phaseolus vulgaris (common bean) and other hosts under acidic conditions (Graham 1992; Martínez-Romero et al. 1991). Thus, $R$. tropici CIAT899 represents a good model to search for genes involved in acid toler- 
ance and to determine their role in symbiosis (Vinuesa et al. 2003). The current knowledge of $\mathrm{pH}$-regulated genes in rhizobia is still poor, despite their agricultural relevance. Proteome analyses using two-dimensional gel electrophoretic analysis reveal differential protein synthesis after $\mathrm{pH}$ shifts (Aarons and Graham 1991; Peick et al. 1999). Mutagenesis with the transposon Tn5 and selection of mutants on acidified media was used to characterize acid-sensitive mutants in $R$. leguminosarum (Chen et al. 1993b). It has been shown that the $R$. tropici gshB-like gene and Sinorhizobium meliloti actA, actP, exoH, exoR, act $S, a c t R$, and $p h r R$ are essential for growth at low $\mathrm{pH}$ (Glenn et al. 1999; Riccillo et al. 2000). More recently, Vinuesa and associates (2003) reported the isolation of additional Tn5-induced acid-sensitive mutants of $R$. tropici CIAT899, all of which displayed symbiotically defective phenotypes in terms of nodulation competitiveness, nodule development, and $\mathrm{N}_{2}$ fixation on $P$. vulgaris. Strain 899-PV4 was shown to carry a single $\operatorname{Tn} 5$ insertion at the $5^{\prime}$ end of atv $A$, an ortholog of the chromosomal virulence gene $a c v B$ of Agrobacterium tumefaciens, which is required by the bacteria for both a proficient interaction with plants and for acid tolerance (Vinuesa et al. 2003).

In this study, we present a genetic analysis as well as a phenotypic characterization of the locus disrupted by the Tn5 insertion in strain 899-PV9, which bears significant sequence homology with the ubiquitous superfamily of $\mathrm{ClC}^{-} \mathrm{Cl}^{-}$channel proteins and $\mathrm{Cl}^{-} / \mathrm{H}^{+}$antiporters (Accardi and Miller 2004; Chen 2005), and of a gene located downstream that is involved in membrane lipid modifications, with relevance for acid tolerance and symbiosis.

\section{RESULTS}

\section{Isolation of cosmids that restore symbiotic proficiency in strain 899-PV9.}

A symbiotically-defective mutant of $R$. tropici CIAT899, obtained by random transposon mutagenesis, was designated 899-PV9. When mutant 899-PV9 was inoculated on P. vulgaris plants, nodules were not fully developed, were irregular in size, lacked lenticels, and did not express nitrogenase activity. Southern blot analysis (not shown) confirmed that the observed phenotype of this strain is due to a single Tn5 insertion, which was localized between nucleotides C1763 and T1764 of the sequence (AY954450) reported herein (Fig. 1A). Mapping of the insertion junction site was achieved by sequencing the flanking regions of plasmid p899PV9ESK, which contains the Tn5 insertion of strain 899-PV9 cloned as an EcoRI fragment, using primer Tn5-77/58EB (Vinuesa et al. 2003), which reads outwardly from the Tn5 insertion sequence elements.

Several symbiotically proficient transconjugants were recovered after complementation of the mutant strain with a cosmid library. The cosmids isolated from these transconjugants were identical in their restriction patterns, after digestion with different enzymes. One of these cosmids, named pPV9cos2, was digested with EcoRI, was transferred to a nylon membrane, and was hybridized with digoxigenin (DIG)-labeled p899PV9PCR. The resulting hybridizing fragment (approximately 6.2 kb) was subcloned into pSK, yielding pPV9EG-SK, and was subjected to DNA sequencing.

\section{Sequence analyses and characterization of orf 2 and orf 3.}

Using different computer programs, an analysis of a 3,761bp EcoRI-ClaI sequence complementing mutant PV9-899 (accession number AY954450) revealed four open reading frames (ORF) with high coding probability, as predicted by FrameD (Fig. 1A). ORF 1 through 3 are transcribed in the same orientation, while orf4 is transcribed convergently with respect to orf 3. orf1 and orf4 were truncated at their 5 ' ends. The genetic analysis presented herein targeted $\operatorname{orf} 2$ and $\operatorname{orf} 3$, which are the ORFs that could be affected by the Tn 5 insertion in mutant 899-PV9 (Fig. 1).

In frame +2 , at position 785, a 1,368-bp ORF (orf2) begins that is predicted to encode a $48.6-\mathrm{kDa}$ product that, according to homology searches with the BLASTP program, showed highly significant sequence similarity to $\mathrm{ClC}$ chloride channel proteins from diverse $\beta$-proteobacteria Burkholderia cepacia (E value $\mathrm{e}^{-104}, 49 \%$ identity, $64 \%$ similarity), Ralstonia solanacearum (E value $\mathrm{e}^{-103}, 49 \%$ identity, $64 \%$ similarity), and the $\gamma$-proteobacteria Pseudomonas syringae (E value $\mathrm{e}^{-103}, 45 \%$ identity, $62 \%$ similarity), Salmonella typhimurium (E value $2 \mathrm{e}^{-55}, 27 \%$ identity, $42 \%$ similarity), and $E$. coli (E value $4 \mathrm{e}^{-45}, 20 \%$ identity, $35 \%$ similarity). The product encoded by orf 2 belongs to the voltage-gated chloride channel and antiporter protein family (COG0038). They are integral membrane proteins with inner membrane localization in gram-negative bacteria. The rhizobial $\mathrm{ClC}$ chloride channel homolog is predicted to have 10 transmembrane helices, with both $\mathrm{N}$ - and $\mathrm{C}$-terminal domains residing in the cytoplasm and containing the sequence motifs corresponding to the ion-binding site and gating region of the solved E. coli and Salmonella typhimurium ClC protein structures (Fig. 1B, part I). This superfamily of ion channels and antiporters is found in both prokaryotic and eukaryotic cells, including most of the $\alpha$-proteobacterial genomes sequenced to date. One of the two ClC paralogs found in E. coli, named $\mathrm{ClC}$-ec1, has been proposed to act as an electrical shunt for an outwardly directed proton pump that is linked to amino acid decarboxylation as part of the extreme acid-resistance response of this bacterium (Iyer et al. 2002). Protein sequence alignments and secondary structure analyses showed a high conservation (Fig. 1B, parts I through III), including the $R$. tropici residue E129, which, in the homologous $\mathrm{ClC}$ chloride channels from E. coli and S. typhymurium, is the one responsible for gating, according to X-ray crystallographic studies (Dutzler 2004; Dutzler et al. 2002). Therefore, based on the highly significant sequence similarity of $\operatorname{orf} 2$ to $\mathrm{ClC}$ chloride channels and antiporters, we named the former locus sycA, for symbiosis-assisting $\mathrm{ClC}$ homolog. The intergenic spacer (IGS) between orf1 and orf 2 was analyzed using the neural network for promoter prediction (NNPP) server, which located a putative promoter sequence upstream of the sycA start codon (sites 727 to $772, r=0.81$ ).

A 845-bp-long ORF (orf3) starts in frame +1 at position 2,611 and is predicted to encode a $31.78-\mathrm{kDa}$ product, with highly significant sequence similarity to a putative aspartyl/ asparaginyl $\beta$-hydroxylase from a Mesorhizobium sp. (E value $9 \mathrm{e}^{-90}, 64 \%$ identity, $76 \%$ similarity) and Azotobacter vinelandii (E value $4 \mathrm{e}^{-63}, 49 \%$ identity, 65\% similarity) and a lower similarity to lipid A-myristate $\beta$-hydroxylase (LpxO) from Salmonella typhimurium (E value $5 \mathrm{e}^{-23}, 35 \%$ identity, $51 \%$ similarity). LpxO has been shown to be responsible for the 2-hydroxylation of myristate in lipid A (Gibbons et al. 2000). Sequence analyses predicted a cytoplasmic localization for the Orf3, with $\mathrm{N}$ - and $\mathrm{C}$-terminal hydrophobic domains. The catalytic domain of this aspartyl/asparaginyl $\beta$-hydroxylase protein family is well conserved (Fig. 1C). In particular, histidine residue H164 is thought to be an iron ligand and, therefore, essential for the function of the protein (Jia et al. 1994). A maximum likelihood phylogenetic reconstruction based on selected protein sequences of this family found in divergent bacteria (data not shown) revealed that the putative aspartyl/asparaginyl $\beta$-hydroxylase from $R$. tropici is located in a different clade than the LpxO protein from Salmonella typhimurium. This inference suggests that $\mathrm{LpxO}$ and $\mathrm{Orf} 3$ might have slightly different functions or substrate specificities, 
although they clearly belong to the same protein superfamily (COG3555). The IGS between sycA and orf3 was analyzed using the NNPP server, which predicted two possible promoter sequences upstream of orf 3 (sites 2,306 to 2,351, $r=0.98 ; 2,419$ to $2,464, r=0.94$ ). This promoter prediction is consistent with a monocistronic organization of the transcript encoded by $s y c A$, which is also supported by reverse transcription-polymerase chain reaction (RT-PCR) experiments, complementation analyses, and the phenotype observed by two-dimensional thin-layer chromatography (2D-TLC) analyses of radiolabeled lipid extracts (discussed below). Based on the evidence gained from the latter experiments, we named orf 3 ols $C$, for ornithine lipid synthesis gene $\mathrm{C}$.

\section{RT-PCR of the IGS between $s y c A$ and ols $C$ confirms that both genes are independently transcribed.}

An RT-PCR experiment was designed to determine the transcriptional organization of $s y c A$ and olsC (Fig. 1D). For this purpose, RNA was isolated from $R$. tropici CIAT899 cells grown in PY broth (Noel et al. 1984) to the early stationary phase and was used to synthesize cDNA with random hexamers as primers. This cDNA was used as template for PCR amplification experiments with primers PV9-2000f and PV92985r, which bind up- and downstream of the IGS region (Fig. 1A). No amplification product was detected (Fig. 1D), which suggests that both ORF are independently transcribed under these conditions and making it unlikely that the Tn5 insertion

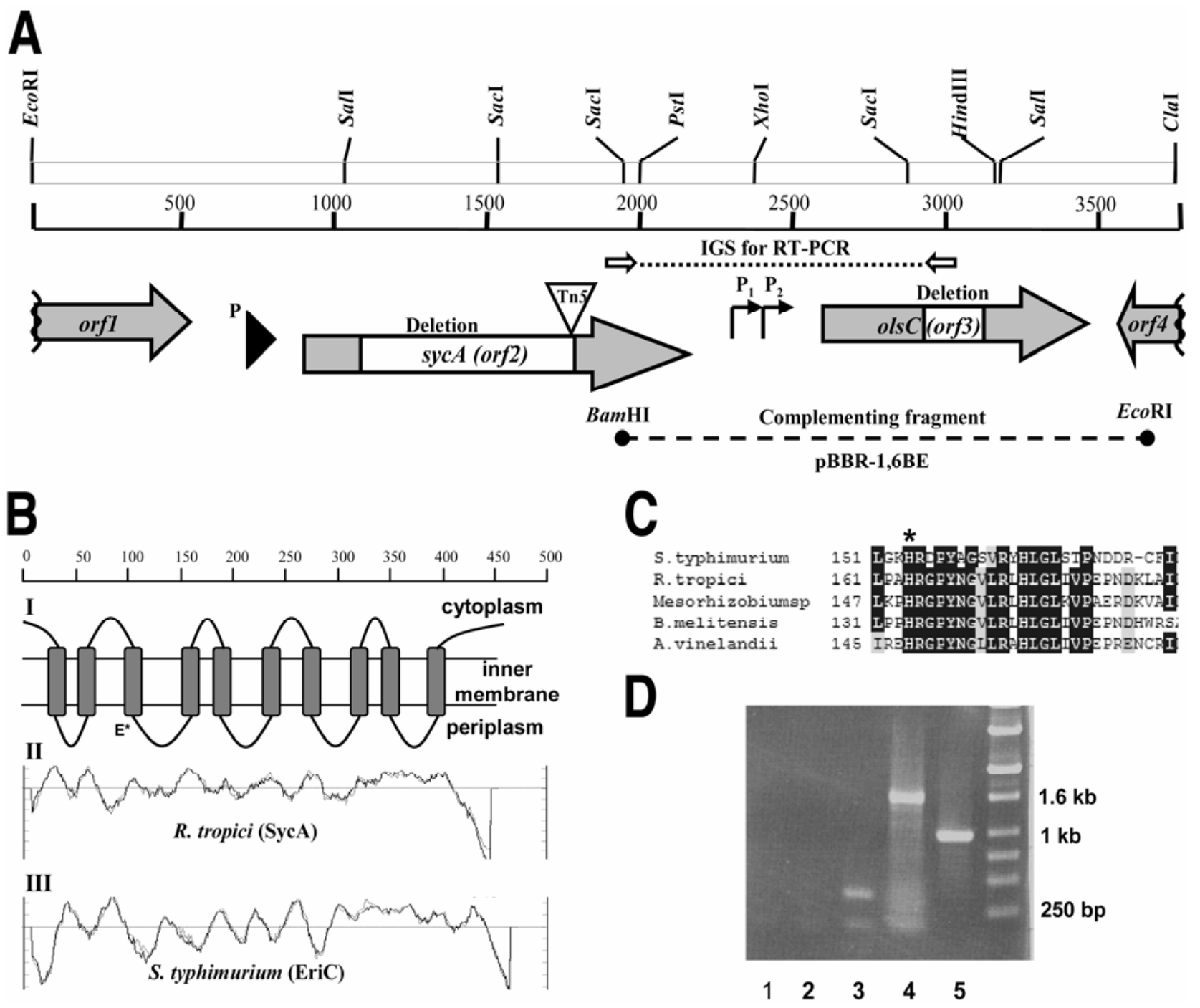

Fig. 1. A, Genetic and physical maps of the 3,761-bp EcoRI-ClaI region from Rhizobium tropici CIAT899 analyzed in this study (accession number AY954450). A, Selected restriction sites. Four open reading frames (ORF) (represented by arrows) were detected. The site of the Tn5 insertion located in sycA between nucleotides C1763 and T1764 is indicated by an open triangle. Nonpolar deletion mutants lacking the regions shown in white were generated in $s y c A$ and $o l s C$. Predicted promoters are shown as thin arrows. The dotted line represents the intergenic spacer between $s y c A$ and $o l s C$ subjected to reverse transcriptase-polymerase chain reaction (RT-PCR) analysis (shown in D). The dashed line shows the location of the 1.66-kb BamHI-EcoRI fragment cloned into pBBR-MCS5 and used to complement strain 899-olsC $\Delta 1$. B, Transmembrane topology predicted by Predictprotein for SycA (panel I); the conserved residue E129 (marked with asterisk) is located in the gating region of EriC (Dutzler et al. 2003). Panels II and III show hydrophobicity plots generated by TmPred for the $R$. tropici CIAT899 ClC homolog sycA (II) compared with that for the ClC exchange transporter (EriC) from Salmonella typhimurium (III). C, Partial sequence alignment of R. tropici, Mesorhizobium sp. (ZP 00193099), Brucella melitensis (NP 539381), Azotobacter vinelandii (ZP 00090437) putative aspartyl/asparaginyl $\beta$-hydroxylase sequences, and $\mathrm{LpxO}\left(\mathrm{Fe}^{2+} / \alpha\right.$-ketoglutarate-dependent dioxygenase $)$ from Salmonella typhimurium (AAF87784). Residue His164 is highly conserved as part of the catalytic domain (Jia et al. 1994). Identical residues are underlined in black, and similar residues are shaded in gray. D, The RT-PCR experiment shows no PCR amplification of the intergenic spacer (IGS) between $s y c A$ and olsC (lane 1), which suggests that both ORF are independently transcribed under these conditions. No amplification in the negative control (lane 2). Positive controls include the PCR amplification of an internal fragment from olsC (lane 3) and the 16S rDNA gene (lane 4), when using cDNA as template, or amplification of the IGS region, when using genomic DNA as template (lane 5). 
in $s y c A$ has a polar effect on olsC. However, the IGS region could be amplified with PV9-2000f and PV9-2985r when genomic DNA was used as template. The presence of an internal fragment of olsC and 16S rDNA in the cDNA template was confirmed by PCR amplification of these genes, demonstrating a proper cDNA synthesis. In the negative control without reverse transcriptase, no amplification product was observed, which excludes the possibility of contamination by $R$. tropici genomic DNA.
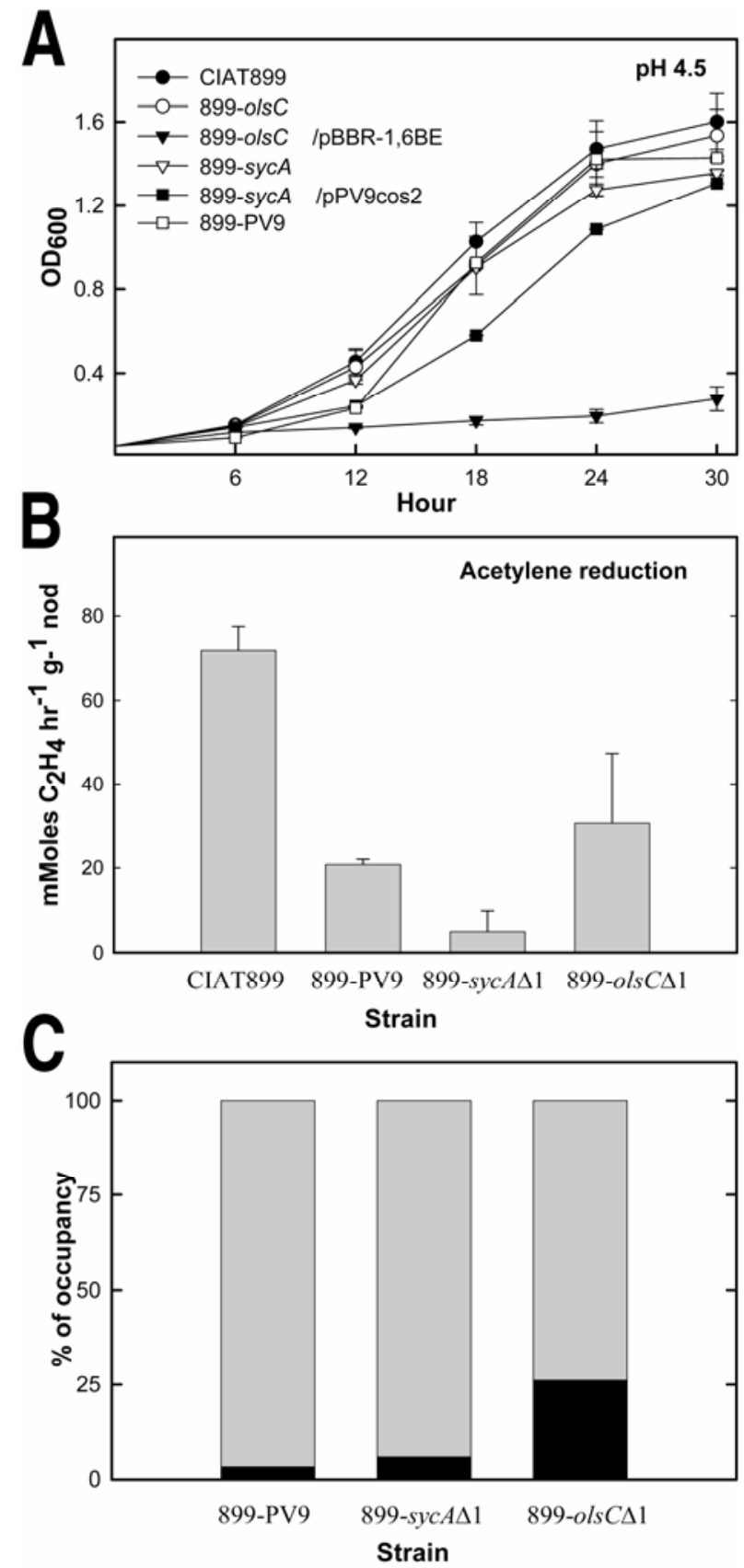

Fig. 2. Phenotypes displayed by several Rhizobium tropici strains used in this study. A, growth of $R$. tropici strains on PY media at $\mathrm{pH} 4.5$. Values are the mean \pm SD of four independent experiments. B, Mean acetylene reduction of nodulated roots inoculated with strains 899-PV9, 899sycA $\Delta 1$, and 899-olsC $\Delta 1$ in comparison to the parental strain CIAT899. Values are the mean \pm SD of three repetitions in two independent experiments. C, Percentage of nodules occupied by mutant strains (black) against reporter strain CIAT899-G1 (gray) in a 10:1 coinoculation experiment (in excess of mutants), using low-inoculum titers (approximately 500 CFU per plantlet).
Construction of nonpolar deletions in sycA and ols C and phenotypic characterization of the mutant strains.

We generated a nonpolar mutation in $s y c A$ by deletion of a 991-bp fragment that embraces nearly the whole gene, including the predicted gating region. To construct this mutant, plasmid pKR $\Delta 02$ was transferred into CIAT899. Double recombinants were selected for the loss of sensitivity to sucrose, and the resulting deletion was confirmed by PCR with primers PV9-524f-H and PV9-2272r-E (data not shown). The mutant obtained was designated $899-s y c A \Delta 1$. This strain was able to grow in $20 \mathrm{E}$ or PY media acidified to $\mathrm{pH} 4.5$ at similar rates as the parent strain (Fig. 2A). However, the nodules it formed on bean plants were poorly developed ( 21 days postinoculation [dpi]), lacked lenticels, were whitish (Fig. 3A and B) and presented a 14-fold decrease in nitrogen fixation in comparison with the parent strain, as revealed by the acetylene reduction assay (Fig. 2B). The nodulation competitiveness of 899$s y c A \Delta 1$ against the gusA-tagged reporter strain CIAT899-G1 in a 10:1 coinoculation experiment (in favor of the mutant) showed that only $5.9 \%$ of the nodules were occupied by the former (Fig. 2C). Coinoculations of CIAT899 and CIAT899G1 resulted in percentages of GUS-expressing nodules that reflected the proportion of gusA-tagged reporter cells in the inoculum mixture, as previously reported (Vinuesa et al., 2003). The symbiotic phenotypes displayed by this strain correspond to those observed in mutant 899-PV9. Further analyses using light and transmission electron microscopy (TEM) revealed that both mutants were able to enter the nodules but were unable to form stable symbiosomes. TEM micrographs of nodules induced by $899-s y c A \Delta 1$ showed poor invasion of plant cells, accumulation of polyhydroxybutyrate granules within

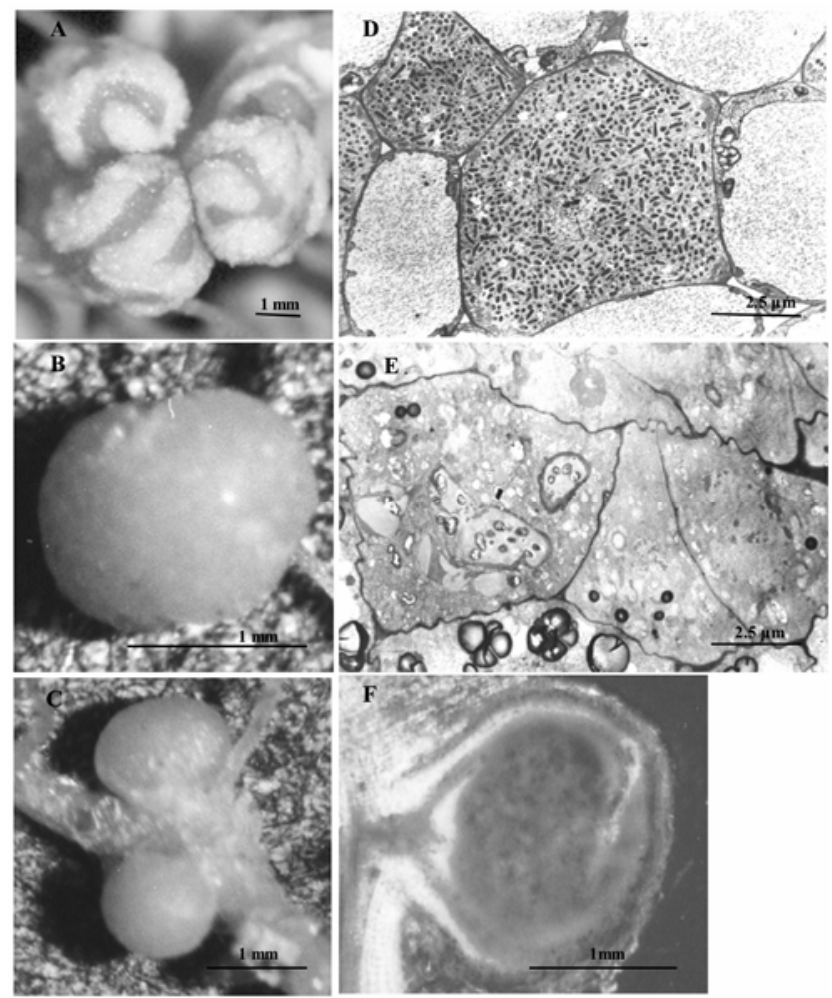

Fig. 3. Macroscopic aspect of nodules induced by strains A, CIAT899, B, mutant 899-sycA $\Delta 1$, and $\mathbf{C}$, mutant $899-o l s C \Delta 1$ on Phaseolus vulgaris plants (21 days postinoculation). Electron micrographs reveal drastic differences in the levels of invasion presented by $\mathbf{D}$, parent strain and $\mathbf{E}$, mutant $899-s y c A \Delta 1$. Notice the accumulation of polyhydroxybutyrate granules in bacteroids of the latter. F, Mutant $899-o l s C \Delta 1$ also shows reduced levels of invasion, as revealed by light microscopy. 
bacteroids, and presence of amyloplasts in the host cells, whereas the parent strain was able to fully invade plant cells (Fig. 3D and E). The symbiotic proficiency of mutant 899$s y c A \Delta 1$ was restored when cosmid pPV9cos 2 was provided in trans (data not shown).

A partial deletion (211 bp long) of the region containing the predicted catalytic domain of OlsC was generated using plasmid pKR $\Delta 03$, following the same procedure mentioned for $s y c A$. The resulting strain $(899-o l s C \Delta 1)$ was confirmed to carry the deletion, by PCR with primers PV9-2571f-E and PV9-3622r-H (data not shown). Mutant 899-olsC $\Delta 1$ was able to grow in $20 \mathrm{E}$ or PY media acidified to $\mathrm{pH} 4.5$ at a similar rate as the parent strain (Fig. 2A). Nodules of bean plants inoculated with this strain $(21 \mathrm{dpi})$ were poorly developed $\left(\mathrm{Ndv}^{-}\right)$ and lacked lenticels (Fig. 3C). These nodules also showed reduced levels of nitrogen fixation (about 50\%), when compared with the wild-type strain CIAT899, as determined by acetylene reduction assays (Fig. 2B). When 899-olsC 1 was coinocu-

Table 1. Membrane lipid composition of Rhizobium tropici CIAT899 wild type, mutant 899-olsC $\Delta 1$, complemented strain 899-olsC $1 / \mathrm{pBBR}-1,6 \mathrm{BE}$, and mutant containing the empty vector 899 -ols $C \Delta 1 /$ pBBR-MCS5 ${ }^{\text {a }}$

\begin{tabular}{|c|c|c|c|c|}
\hline \multirow[b]{2}{*}{ Lipid } & \multicolumn{4}{|c|}{ Composition (\% total $\left.{ }^{14} \mathrm{C}\right)$} \\
\hline & CIAT899 & 899-olsC $\Delta 1$ & 899-olsC $\Delta 1 / \mathrm{pBBR}-1,6 \mathrm{BE}$ & 899-ols $C \Delta 1 / 899-o l s C \Delta 1 /$ \\
\hline pBBR-MCS5PC & $40.3 \pm 4.7$ & $47.8 \pm 6.0$ & $32.5 \pm 1.5$ & $37.4 \pm 5.5$ \\
\hline Phosphatidylglycerol (PG) & $11.9 \pm 2.1$ & $10.7 \pm 1.9$ & $12.7 \pm 1.3$ & $11.2 \pm 0.2$ \\
\hline Cardiolipin (CL) & $2.9 \pm 2.0$ & $2.6 \pm 0.8$ & $2.9 \pm 0.3$ & $3.2 \pm 1.4$ \\
\hline Phosphatidylethanolamine (PE) & $23.4 \pm 3.8$ & $16.3 \pm 4.9$ & $33.4 \pm 0.4$ & $26.2 \pm 1.7$ \\
\hline $\mathrm{S} 1^{\mathrm{b}}$ & $2.7 \pm 2.7$ & $7.2 \pm 1.8$ & n.d. & $10.7 \pm 3.0$ \\
\hline $\mathrm{S} 2$ & $4.5 \pm 1.9$ & $15.3 \pm 1.1$ & $0.3 \pm 0.2$ & $11.3 \pm 0.8$ \\
\hline P1 & $6.3 \pm 3.0$ & n.d. & $6.8 \pm 2.9$ & n.d. \\
\hline P2 & $8.1 \pm 4.9$ & n.d. & $11.4 \pm 1.4$ & n.d. \\
\hline
\end{tabular}

${ }^{a}$ Values are the mean \pm standard deviations of three independent experiments. n.d. $=$ not detected.

${ }^{\mathrm{b}} \mathrm{S} 1, \mathrm{~S} 2, \mathrm{P} 1$, and P2 denote four additional components detected in the chromatogram of $R$. tropici CIAT899.
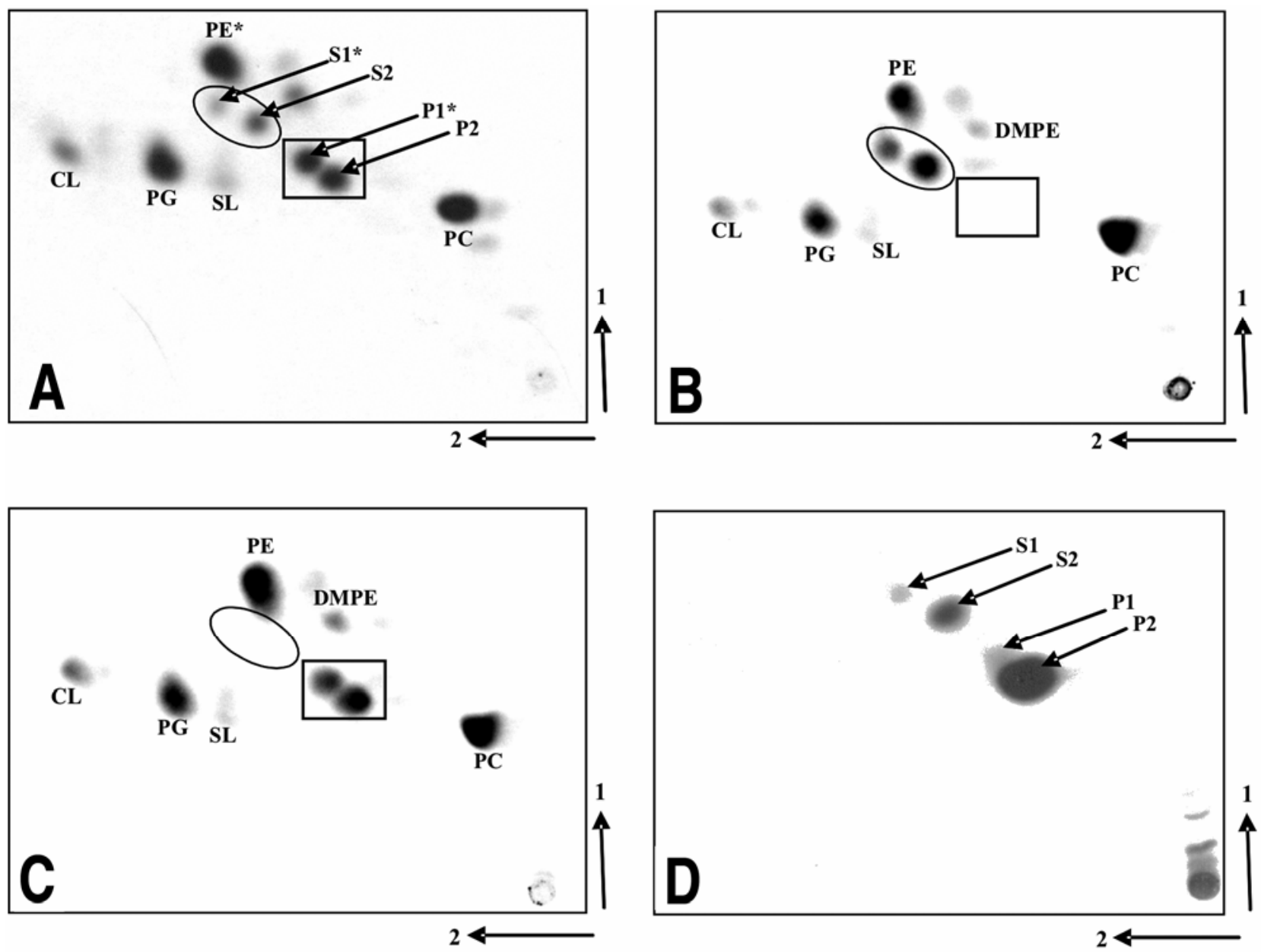

Fig. 4. Membrane lipid analysis of Rhizobium tropici strains. Separation of $\left[{ }^{14} \mathrm{C}\right]$ acetate-labeled lipids from A, $R$. tropici CIAT899, B, mutant $899-$ ols $C \Delta 1$, and $\mathbf{C}$, complemented mutant $899-$ ols $C \Delta 1 / \mathrm{pBBR}-1,6 \mathrm{BE}$ as well as of $\mathbf{D},\left[{ }^{14} \mathrm{C}\right]$ ornithine-labeled lipids from $R$. tropici CIAT899, using two-dimensional thinlayer chromatography. The lipids cardiolipin (CL), phosphatidylglycerol (PG), sulphoquinovosyl diacylglycerol (SL), phosphatidylethanolamine (PE), dimethylphosphatidylethanolamine (DMPE), and phosphatidylcholine (PC) are indicated. In A, B, and C, ovals surround lipid species S1 and S2, which presumably are substrates for the putative $R$. tropici $\beta$-hydroxylase to form the lipid products (P1 and P2) that are enclosed in rectangular boxes. Asterisks indicate ninhydrin-positive lipids. 
lated with the gusA-tagged reporter strain CIAT899-G1 in a $10: 1$ ratio, only $25 \%$ of the nodules were occupied by the former, which displayed the same $\mathrm{Ndv}^{-}$phenotype as the nodules induced by 899 -ols $C \Delta 1$ (Fig. 2C). Light micrographs of nodules inoculated with mutant 899-olsC $\Delta 1$ (Fig. 3F) revealed lower invasion levels than those achieved by the parent strain CIAT899, although not as drastic as observed for mutant 899sycA $\Delta 1$ (data not shown).

\section{Complementation of mutant 899-ols $C \Delta 1$ with pBBR-1,6BE.}

In order to complement mutant 899-ols $C \Delta 1$, plasmid pBBR1,6BE (Fig. 1A) was constructed and provided in trans. A 1,660-bp BamHI-EcoRI fragment containing olsC and the upstream region with the predicted promoter region was PCRamplified and cloned into pBBR-MCS5. To ensure that the gene is expressed from its native promoter, the fragment was cloned in opposite transcriptional direction to the vector's lac $Z$ promoter. Plasmid pBBR-1,6BE was transferred into mutant 899-olsC $\Delta 1$, and strain 899 -ols $C \Delta 1 / \mathrm{pBBR}-1,6 \mathrm{BE}$ was tested on bean plants for symbiotic performance. The symbiotic proficiency and nitrogen fixation capacity of strain 899ols $C \Delta 1 / \mathrm{pBBR}-1,6 \mathrm{BE}$ was restored to similar levels as exhibited by CIAT899. On near-neutral media ( $\mathrm{pH}$ 6.8), the complemented strain 899-olsC $\Delta 1 / \mathrm{pBBR}-1,6 \mathrm{BE}$ (generation time $(g)=$ $2.8 \mathrm{~h})$ grew similarly to CIAT899 $(g=2.4 \mathrm{~h})$ or mutant 899 ols $C \Delta 1$ with $(g=2.8 \mathrm{~h})$ or without $(g=2.8 \mathrm{~h})$ the empty vector (data not shown). In contrast, when the complemented strain was grown on acidified media at $\mathrm{pH} 4.5$ (Fig. 2A), it presented a significantly increased mean generation time $(g=9.2 \mathrm{~h})$ in comparison to CIAT899 or the mutant 899 -olsC $\Delta 1$ with or without the empty vector $(g \approx 2.9 \mathrm{~h})$. These results suggest that the expression or overexpression (due to copy number) of the gene contained in this $1.66-\mathrm{kb}$ fragment is responsible for the reduced growth under acidic conditions displayed by the complemented strain when carrying plasmid pBBR-1,6BE in trans.

\section{Some membrane lipids}

of $R$. tropici CIAT899 are absent in mutant 899-ols $C \Delta \mathbf{1}$.

Lipid extracts from $R$. tropici CIAT899, mutant 899-olsC $\Delta 1$ carrying the 211-bp deletion in olsC, and the complemented mutant 899 -ols $C \Delta 1$ /pBBR-1,6BE were separated by $2 \mathrm{D}-\mathrm{TLC}$, and individual lipids were quantified (Table 1). Rhizobial membrane phospholipids like phosphatidylethanolamine (PE), dimethylphosphatidylethanolamine, cardiolipin, phosphatidylglycerol, sulphoquinovosyl diacylglycerol, and phosphatidylcholine (PC) were identified based on their relative mobilities and in comparison to the well-characterized lipid profile of $S$. meliloti 1021 (Gao et al. 2004; Weissenmayer et al. 2002). As found for $S$. meliloti 1021 , PC constitutes the major membrane lipid of $R$. tropici CIAT899. In addition to the above-mentioned lipids, four additional components can be detected in the chromatogram of $R$. tropici CIAT899, labeled as S1, S2, P1, and P2 (Fig. 4A). Staining of developed 2D-TLC chromatograms with ninhydrin revealed that $\mathrm{PE}, \mathrm{S} 1$, and $\mathrm{P} 1$ possess primary amino groups (data not shown). The compound S1 shows the same relative mobility as ornithine-containing lipids (OL), which have been characterized previously in $S$. meliloti

Table 2. Bacterial strains and plasmids used in this study

\begin{tabular}{|c|c|c|}
\hline Strain or plasmid & Relevant characteristics $^{\mathbf{a}}$ & Source or reference \\
\hline \multicolumn{3}{|l|}{ Rhizobium tropici strains } \\
\hline CIAT899 & Acid tolerant, $\mathrm{Ap}^{\mathrm{r}}, \mathrm{Nal}^{\mathrm{r}}$ & Martínez-Romero et al. 1991 \\
\hline 899-PV9 & CIAT899 derivative (sycA::Tn5), symbiotically defective, $\mathrm{Sm}^{\mathrm{r}}, \mathrm{Km}^{\mathrm{r}}$ & Vinuesa et al. 2003 \\
\hline CIAT899-G1 & $\begin{array}{l}\text { gusA-tagged CIAT899 derivative carrying a single } \mathrm{mTn} 5 \text { gusA30 insertion, used as } \\
\text { reporter strain in competition experiments, } \mathrm{Sm}^{\mathrm{r}}, \mathrm{Sp}^{\mathrm{r}}\end{array}$ & Vinuesa et al. 2003 \\
\hline 899-syc $A \Delta 1$ & CIAT899 carrying a 991 bp non-polar deletion in sycA & This study \\
\hline 899-sycA $\Delta 1 / \mathrm{pPV} 9 \cos 2$ & 899-sycA $\Delta 1$ carrying the complementing cosmid of $899-\mathrm{PV} 9, \mathrm{Tc}^{\mathrm{r}}$ & This study \\
\hline 899-olsC $\Delta 1$ & CIAT899 carrying a 211-bp nonpolar deletion in olsC & This study \\
\hline 899-olsC $\Delta 1 / \mathrm{pBBR}-1,6 \mathrm{BE}$ & 899-ols $C \Delta 1$ complemented with pBBR-1,6BE & This study \\
\hline 899-olsC $\Delta 1 / \mathrm{pBBR}-\mathrm{MCS} 5$ & 899-ols $C \Delta l$ carrying the vector pBBR-MCS5 & This study \\
\hline \multicolumn{3}{|l|}{ Escherichia coli strains } \\
\hline DH5 $\alpha$ & recA1, $\Delta l a c U 169, \Phi 80 \mathrm{dlacZ} \Delta \mathrm{M} 1$ & Stratagene, La Jolla, CA, U.S.A. \\
\hline S17-1 & $\begin{array}{l}\text { thi pro } h s d R^{-} h s d M^{+} \text {recA, RP4 integrated in the chromosome, 2-Tc::Mu- } \\
\mathrm{Km}:: \operatorname{Tn} 7\left(\mathrm{Tp}^{\mathrm{r}} / \mathrm{Sm}^{\mathrm{r}}\right)\end{array}$ & Simon et al. 1983 \\
\hline \multicolumn{3}{|c|}{${ }^{3}$} \\
\hline pRK2013 & Helper plasmid; $\mathrm{Km}^{\mathrm{r}}$ & Ditta et al. 1980 \\
\hline pK18mob & $\begin{array}{l}\text { Conjugative suicide vector with } \mathrm{Km}^{\mathrm{r}} \text { lac } Z \text { markers used for positive selection of } \\
\text { single recombinants }\end{array}$ & Schäfer et al. 1994 \\
\hline pK18mobsacB & $\begin{array}{l}\text { Conjugative suicide vector with } \mathrm{Km}^{\mathrm{r}} l a c Z \text { and } s a c B \text { markers used for positive } \\
\text { selection of double recombinants }\end{array}$ & Schäfer et al. 1994 \\
\hline pBBR-MCS5 & Mobilizable broad host range cloning vector, $\mathrm{Gm}^{\mathrm{r}}$ & Kovach et al. 1995 \\
\hline pCR II & PCR cloning vector & Invitrogen, Carlsbad, CA, U.S.A. \\
\hline pSUP1011 & Mobilizable suicide plasmid for $\mathrm{Tn} 5$ mutagenesis & Simon et al. 1985 \\
\hline pBluescript II SK (pSK) & Standard cloning and sequencing vector, ${\text { lac } Z \mathrm{Ap}^{\mathrm{r}}}$ & Stratagene \\
\hline p899PV9ESK & $\begin{array}{l}\text { 12-kb EcoRI fragment from strain 899-PV9, containing the Tn5 insertion, cloned } \\
\text { in pSK. Ap }{ }^{\mathrm{r}}, \mathrm{Km}^{\mathrm{r}}\end{array}$ & This study \\
\hline p899PV9E-PCR & $\begin{array}{l}\text { pSK plasmid containing the flanking region of p899PV9ESK and used for DIG- } \\
\text { labeling. } \mathrm{Ap}^{\mathrm{r}}\end{array}$ & This study \\
\hline P859PV9E6-SK & $\begin{array}{l}\text { pSK construct containing the } 6.2-\mathrm{kb} E c o \mathrm{RV} \text { fragment hit by the } \mathrm{Tn} 5 \text { insertion in } \\
899-\mathrm{PV} 9\end{array}$ & This study \\
\hline pPV9 $\cos 2$ & Cosmid complementing 899-PV9, $\mathrm{Tc}^{\mathrm{r}}$ & This study \\
\hline $\mathrm{pKR} \Delta 02$ & $\begin{array}{l}\text { Integrative mutagenizing plasmid based on pK18mobsacB used to construct strain } \\
899-s y c A \Delta 1\end{array}$ & This study \\
\hline $\mathrm{pKR} \Delta 03$ & $\begin{array}{l}\text { Integrative mutagenizing plasmid based on } \mathrm{pK} 18 \text { mobsacB used to construct strain } \\
\text { 899-ols } \mathrm{C} \Delta 1\end{array}$ & This study \\
\hline pBBR-1,6BE & $\begin{array}{l}\text { 1.66-kb Bam HI-EcoRI fragment cloned into pBBR-MCS5 used for complementing } \\
\text { mutation on strain } 899 \text {-ols } C \Delta 1\end{array}$ & This study \\
\hline
\end{tabular}

\footnotetext{
${ }^{a} \mathrm{Ap}, \mathrm{Nal}, \mathrm{Sm}, \mathrm{Km} . \mathrm{Sp}, \mathrm{Tc}$, and Tp = ampicillin, nalidixic acid, streptomycin, kanamycin, spectinomycin, tetracycline, and trimethoprim.
} 
(Gao et al. 2004; Weissenmayer et al. 2002). Since OL is also a ninhydrin-positive compound, we suggest that S1 might be the corresponding OL from $R$. tropici CIAT899. The lipid composition of the Tn5-generated mutant 899-PV9 and that of the deletion mutant $899-s y c A \Delta 1$, both defective in the predicted chloride channel protein, were indistinguishable from that of the wild type (data not shown). Although the lipid composition of mutant 899-olsC $\Delta 1$ resembles that of the wild type (Fig. 4B), compounds $\mathrm{P} 1$ and $\mathrm{P} 2$, which together comprised nearly $15 \%$ of the wild-type membrane lipids, are absent in mutant 899-ols $C \Delta 1$ (Table 1). In contrast, the wild type has only minor levels of $\mathrm{S} 1$ and $\mathrm{S} 2$ (7.2\% of total membrane lipids), whereas in mutant 899 -ols $C \Delta 1$, these two lipids comprise $22.4 \%$ of the total lipid detected. If the mutant is complemented in trans with pBBR-1,6BE (Fig. 4C), again, P1 and P2 are formed in relatively high amounts (more than $18 \%$ of total membrane lipids), whereas $\mathrm{S} 1$ and $\mathrm{S} 2$ are practically absent from this strain. These data suggest that OlsC is required for the formation of lipids P1 and P2.

Incorporation experiments with radiolabeled ornithine demonstrated that from all the membrane lipids, in $S$. meliloti, only OL become labeled, indicating that ornithine is specifically and exclusively incorporated into OL (Gao et al. 2004). Analysis of the lipid profile from $R$. tropici CIAT899 that had been labeled with $\left[1-{ }^{14} \mathrm{C}\right]$ ornithine indicates that four compounds have incorporated radiolabeled ornithine (Fig. 4D). The relative mobilities of the radiolabeled compounds coincide with the relative mobilities found for lipids $\mathrm{S} 1, \mathrm{~S} 2, \mathrm{P} 1$, and $\mathrm{P} 2$. Therefore, we conclude that all four of these lipids are distinct classes of OL of $R$. tropici CIAT899.

\section{DISCUSSION}

In this work, we report two novel genes of Rhizobium tropici CIAT899 that were shown to be required for the establishment of a fully developed $\mathrm{N}_{2}$-fixing symbiosis with bean plants. The microscopy analyses performed on mutant 899sycA $\Delta 1$, which carries a deletion in the putative chloride channel encoded by $s y c A$, suggests that the observed decrease in nodule development and nitrogen fixation is probably due to its failure to invade plant cells and to form stable symbiosomes. This is the first report showing that a rhizobial homolog of the $\mathrm{ClC}$ family of $\mathrm{Cl}^{-}$channels and $\mathrm{Cl}^{-} / \mathrm{H}^{+}$antiporters is essential for the establishment of a fully proficient symbiotic interaction with its legume host but not for growth under freeliving conditions. With the notable exception of E. coli, the molecular and physiological functions of dozens of prokaryotic $\mathrm{ClC}$ homologs recently uncovered by genome sequencing projects are still unknown. It is worth noting that the $\mathrm{ClC}-\mathrm{ec} 1$ (or EriC) protein of E. coli was recently shown not to be an ion channel, but rather a $\mathrm{H}^{+} / \mathrm{Cl}^{-}$exchange transporter, demonstrating that the structural boundary separating transporters and channels is not as clearcut as previously thought (Accardi and Miller 2004; Chen 2005). The E. coli genome has two $\mathrm{ClC}$ homologs. When either one of these genes was individually deleted, no notable phenotype was observed. However, a double knock-out strain displayed a dramatic reduction in cell survival and amino acids transport under acid shock (Iyer et al. 2002). We have recently cloned a second $\mathrm{ClC}$-like paralog from CIAT899 (as found in the genomes of many other $\alpha$-Proteobacteria, including Agrobacterium tumefaciens C58, Brucella suis 1330, Brucella melitensis 16M, Bradyrhizobium japonicum USDA110, and Mesorhizobium loti MAFF303099 but not $S$. meliloti 1021), which suggests that the $\mathrm{ClC}$ paralogs might perform different functions in the cell under different physiological conditions and might be differentially expressed. Our complementation results demonstrate that the paralog $(s y c A)$ mutated in this study is required for a proficient symbiotic interaction with bean plants but, apparently, not for acid tolerance or growth under free-living conditions. However, at this point, we cannot define if the mutations made in $s y c A$ have a direct or indirect effect on the symbiotic phenotype observed in strains 899-PV9 and 899-sycA $\Delta 1$. At this point and based on the evidence gained from TEM data, we cannot state whether the mutation is affecting bacteroid release from infection threads, symbiosome proliferation, or stability. Mutations in the second paralogous gene, the construction of a double mutant, and analysis of transcriptional reporter gene fusions would be very valuable to gain a better understanding of the functions of these genes.

It has recently been shown that $R$. leguminosarum mutants blocked in amino acid transporters, present poorly developed nodules and reduced $\mathrm{N}_{2}$ fixation and the bacteroids are saturated with dicarboxylic acids and polyhydroxybutyrate granules (Lodwig et al. 2003). Since the peribacteroid space is acidic and the mutant $899-s y c A \Delta 1$ displayed a similar phenotype to that observed for the $R$. leguminosarum mutant, it is tempting to speculate that SycA might be involved in the adaptation of $R$. tropici bacteroids to the symbiosome's milieu, probably in relation with the electrophysiology of bacteroid membranes, which in turn may affect key aspects of cellular homeostasis like the internal $\mathrm{pH}$ of bacteroids or the transport of metabolites across their cellular membranes. Since $\mathrm{ClC}$ channels and antiporters are highly selective for chloride anions (Accardi et al. 2004; Chen 2005), this would imply that $\mathrm{Cl}^{-}$could play a key role in symbiosome physiology. If so, it remains to be uncovered.

Only two previous works describe the phenotypes of microbial cells carrying mutations in $\mathrm{ClC}$ homologs in relation to their interaction with eukaryotic hosts. Mutations in $c l c$ - $a$ from the human pathogenic yeast Cryptococcus neoformans resulted in attenuated virulence in a mouse cryptococcosis model. This attenuation resulted from the lack of expression of two important virulence factors, capsule and laccase (Zhu and Williamson 2003). In contrast, deletion of the single $\mathrm{ClC}$ ortholog found in Vibrio cholerae enhanced intestinal colonization in infant mice. This gene was found to confer mild resistance to acid when $\mathrm{pH}$ was adjusted with $\mathrm{HCl}$ but not with other acids (Ding and Waldor 2003). Clearly, much research is still needed to provide a basic understanding of the molecular and physiological functions of the diverse $\mathrm{ClC}$ homologs found across prokaryotic phyla.

It has been speculated that certain membrane lipids might be important for the establishment of a successful symbiosis (de Rudder et al. 1997). This idea has been supported by the observations that mutants of $S$. meliloti lacking phosphatidylcholine (PC) are unable to form nitrogen-fixing nodules on alfalfa (López-Lara et al. 2003; Sohlenkamp et al. 2003) and that mutants of Bradyrhizobium japonicum with diminished levels of PC present a reduced number of bacteroids within infected plant cells (Minder et al. 2001). Since PC comprises 50 to $60 \%$ of the lipids in membranes of $S$. meliloti or Bradyrhizobium japonicum and OL about $20 \%$ in $R$. tropici, one might expect that major changes in membrane lipid composition, either by mutations or by increased copy number of genes involved in their biosynthesis, could affect the structural properties of cell membranes and, as a consequence, the proper functioning of membrane-associated proteins.

$R$. tropici CIAT899 produces four different classes of OL (S1, S2, P1, and P2). As lipid S1 is ninhydrin-positive and migrates in an identical way as the well-characterized OL (Geiger et al. 1999) from $S$. meliloti in 2D-TLC, we expect that S1 presents a similar or identical structure as sinorhizobial OL. In contrast, the S2, P1, and P2 classes of OL, in this order, migrate 
more slowly in both dimensions of 2D-TLC systems and, therefore, must be increasingly more polar due to still unknown modifications by functional groups.

Mutant 899-olsC $\Delta 1$ forms more $\mathrm{S} 1$ and $\mathrm{S} 2$ than wild type and lacks $\mathrm{P} 1$ and $\mathrm{P} 2$, whereas the complemented mutant 899 ols $C \Delta 1 / \mathrm{pBBR}-1,6 \mathrm{BE}$ presented mainly $\mathrm{P} 1$ and $\mathrm{P} 2$ and a nearcomplete lack of $\mathrm{S} 1$ and $\mathrm{S} 2$. These data show that OlsC is required for the formation of $\mathrm{P} 1$ and $\mathrm{P} 2$ and suggest that $\mathrm{OlsC}$ might consume $\mathrm{S} 1$ and $\mathrm{S} 2$. This is consistent with a model in which the predicted $\beta$-hydroxylase encoded by ols $C$ converts the ninhydrin-positive compound $\mathrm{S} 1$ to the ninhydrin-positive compound $\mathrm{P} 1$ and also the ninhydrin-negative compound $\mathrm{S} 2$ to the ninhydrin-negative compound $\mathrm{P} 2$, presumably by hydroxylation at a still-unknown position in these molecules. As S1 and $\mathrm{S} 2$ both seem to function as in vivo substrates for the OlsC reaction, one might expect that $\mathrm{S} 1$ and $\mathrm{S} 2$ would have similar chemical structures and that, therefore, S2 might be a modified version of the OL known to date. The nonreactivity of S2 with ninhydrin might be due to an additional, so far unknown modification at the $\delta$-amino group of its ornithine residue. Similarly, as P1 and P2 might be both products of an in vivo reaction catalyzed by OlsC, again one can expect that $\mathrm{P} 1$ and $\mathrm{P} 2$ would have similar structures, with $\mathrm{P} 2$ having an additional modification at the $\delta$-amino group of its ornithine residue. The near-complete lack of $\mathrm{S} 1$ and $\mathrm{S} 2$ in the case of strain 899ols $C \Delta 1 / \mathrm{pBBR}-1,6 \mathrm{BE}$ can be explained by a more efficient conversion of S1 and S2 to P1 and P2 due to an increased copy number of the gene responsible for the conversion.

Mutant 899 -ols $C \Delta 1$ is acid-tolerant but symbiotically defective. In contrast, the complemented mutant 899-olsC $\Delta 1 / \mathrm{pBBR}$ $1,6 \mathrm{BE}$ was able to restore the symbiotic proficiency but was acid-sensitive. The latter suggests that lipids P1 and P2 are necessary for a successful symbiotic interaction of $R$. tropici CIAT899 with the plant host, whereas lipids S1 and S2 are required for acid tolerance. This hypothesis is consistent with the fact that, in the parent strain, CIAT899 all four distinct classes of OL are present and that this strain is both acid-tolerant and symbiotically proficient.

The analysis performed on mutant 899 -ols $C \Delta 1$ permits us to report for the first time that membrane lipids of $R$. tropici are involved in symbiosis and that the putative $\beta$-hydroxylase encoded by ols $C$ is part of a biosynthesis pathway for membrane lipids not previously described for any species. We demonstrate that $R$. tropici lipid species $\mathrm{S} 1, \mathrm{~S} 2, \mathrm{P} 1$, and $\mathrm{P} 2$ are indeed $\mathrm{OL}$ and that the product encoded by ols $C$ is necessary to convert lipids S1 and S2 to P1 and P2, presumably by hydroxylation at a still-unknown position. Lipids P1 and P2, which presumably carry a hydroxyl group at a still-unkown position, are required for an effective symbiotic interaction with bean plants, while a lack of lipids S1 and S2 was correlated with acid sensitivity. Hydroxylations at the 2-position of fatty acyl residues of membrane lipids such as $\mathrm{PE}$ or OL are known to occur in Burkholderia cepacia and other bacteria (Taylor et al. 1998). Although the molecular functions of OL modifications in $R$. tropici are not understood at this point, a balanced membrane lipid composition of the $R$. tropici cell membranes is required for both the symbiotic interaction with plants and for acid tolerance under free-living conditions. This is the first report of a rhizobial membrane lipid other than phospholipids with relevance for symbiosis.

\section{MATERIALS AND METHODS}

\section{Bacterial strains and plasmids.}

Bacterial strains and plasmids used in the present work are listed in Table 2. Rhizobial strains were grown in PY (Noel et al. 1984), minimal medium (MM) (Kingsley and Bohlool
1992), or in $20 \mathrm{E}$ medium (Werner et al. 1975) at $28^{\circ} \mathrm{C}$. Acidic media at $\mathrm{pH} 4.5$ were buffered with $25 \mathrm{mM}$ Homopipes (Research Organics, Cleveland, OH, U.S.A.). E. coli strains were grown in Luria-Bertani medium at $37^{\circ} \mathrm{C}$ (Sambrook et al. 1989). When needed, antibiotics were added at the following concentrations: kanamycin, $100 \mu \mathrm{g} / \mathrm{ml}$; streptomycin, $150 \mu \mathrm{g} / \mathrm{ml}$; ampicillin (Ap), $50 \mu \mathrm{g} / \mathrm{ml}$; tetracycline, 7.5 $\mu \mathrm{g} / \mathrm{ml}$; gentamicin $(\mathrm{Gm}), 10 \mu \mathrm{g} / \mathrm{ml}$; nalidixic acid (Nal), 20 $\mu \mathrm{g} / \mathrm{ml}$.

\section{Random transposon mutagenesis of $\boldsymbol{R}$. tropici CIAT899, selection \\ of acid-sensitive mutants and cosmid complementation.}

Tn5 mutagenesis of $R$. tropici CIAT899 was carried out using E. coli S17-1 carrying pSUP1021 as donor strain (Simon et al. 1983). Transconjugants carrying the transposon were isolated, and acid-sensitive mutants were selected on different acidified media, as previously described (Vinuesa et al. 2003). A cosmid library of $R$. tropici CIAT899 made in pVK101 (Vargas et al. 1990) was mobilized en masse into CIAT899-PV9, by triparental mating using pRK2013 as helper plasmid (Figurski and Helinski 1979). Transconjugants that restore symbiotic proficiency on common beans were isolated as previously described (Vinuesa et al. 2003).

\section{Standard DNA manipulations.}

Genomic DNA from rhizobial strains was isolated using the GenomicPrep cells and tissues DNA isolation kit (Amersham Biosciences, Buckinghamshire, U.K.), following the manufacturer's instructions. Plasmid DNA from E. coli cultures was isolated with the High pure plasmid isolation kit (Roche, Mannheim, Germany). Restriction endonucleases were purchased from New England Biolabs (Beverly, MN, U.S.A.) and were used according to standard procedures (Sambrook et al. 1989). PCR amplifications were carried out in a Gene Amp PCR system 2700 (Applied Biosystems, Foster City, CA, U.S.A.), using Taq (Roche) or XL polymerase (Applied Biosystems) in a standard 50- $\mu$ l PCR mix as previously described (Vinuesa et al. 1999).

To map the transposon insertion in mutant 899-PV9, total DNA of this strain was digested with EcoRI, was transferred to a nylon membrane, and was hybridized with a DIGlabeled probe generated by the incorporation of DIG-UTP (Roche) into the nptII marker of Tn5 via PCR, as previously described (Vinuesa et al. 2003). The single hybridizing fragment (approximately $14 \mathrm{~kb}$ ) was cloned into pBluescript (pSK), yielding p899PV9ESK. This plasmid was used as template for PCR amplification with primers Tn5-77/58EB (Vinuesa et al. 2003) and M13 universal to map the Tn5 insertion by sequencing the resulting PCR product with the former primer, which reads outwardly from the Tn5 insertion elements. The amplification product was cloned into pSK, yielding p899PV9E-PCR, and was used to generate a hybridization probe of the genomic DNA flanking the Tn5 insertion by DIG-labeling.

Cosmids were isolated and restricted with several enzymes as previously described (Vinuesa et al. 2003). Cosmid pPV9 $\cos 2$ was hybridized with the probe derived from the insert cloned in p899PV9E-PCR, and the resulting hybridizing band was cloned into pSK, yielding pPV9E-SK. Subclones from pPV9E-SK were sequenced with an ABI Prism 3700 automated sequencer, using the universal M13f and M13r primers (Applied Biosystems). PCR primers were subsequently designed to obtain an approximately $8 \times$ coverage of overlapping plasmid subclones and PCR products from which a contig was assembled using SeqManII from the DNASTAR package (Lasergene, Madison, WI, U.S.A.). 
DNA sequence analyses.

ORF with high coding probability were identified on the contig sequence using FrameD, with the $S$. meliloti codon usage table and the pentanucleotide aagga as ribosomal binding site. The BLASTX and BLASTP programs from the nonredundant sequence databases at the National Center for Biotechnology Information were used to search for homology. Protein sequence analyses to predict secondary structure, cell localization, transmembrane domains, conserved motifs, and hydrophobicity profiles were performed using Prosite, ProDom, PsortB, TmPred, PsPred, Pfam, and iProClass program servers. A search for putative promoter regions in intergenic regions was performed using the NNPP server.

\section{Determination of operon structure by RT-PCR.}

RNA from $R$. tropici CIAT899 was isolated using the High pure RNA isolation kit (Roche) according to the manufacturer's instructions, and cDNA was immediately synthesized using the Omniscript RT kit (Qiagen, Hilden, Germany). This cDNA was used as template for PCR amplification of the IGS between $s y c A$ and $o l s C$, using primers PV9-2000f (5'gcagcggc cataccagcatc) and PV9-2985r (5'tcacgccgaaaccgaggag). Positive controls included the amplification of the 16S rDNA gene with primers fD1 and rD1 (Weisburg et al. 1991) and the amplification of a 389-bp internal fragment of olsC using primers PV9-2571f-H (5'ccaagcttcctcceggaccgcac) and PV9-2960r-B (5'ccggatccagcgggtgtcggtgg). To discard the presence of contamination by $R$. tropici genomic DNA, the same master mix used for cDNA synthesis but lacking the retrotranscriptase was used as a negative control for PCR amplification experiments with the primers for the $16 \mathrm{~S}$ rDNA gene and the internal ols $C$ fragment .

\section{Construction}

of nonpolar mutants 899-sycA $\Delta 1$ and 899-ols $C \Delta 1$.

To construct a nonpolar mutant in $s y c A$, PCR amplification of two nonoverlapping approximately 400-bp fragments located at the opposite ends of the ORF (resulting in a 991-bp deletion) were performed using primer pairs (restriction sites underlined) PV9-524f-H (5'gcaagcttgcccgggcggtgtgacg) and PV9-971r-B (5'cggatccggcaacgggcataagaaag) and PV9-1962fB (5' ccggatcctcgctgtcgcgtgctt) and PV9-2272r-E (5'ccgaattcct gccatcggagcgtc) and total DNA of $R$. tropici as template (Fig. $1)$. The same strategy was used to construct a 211-bp deletion in olsC, using primer pairs PV9-2571f-H (5'ccaagcttcctcccg gaccgcac) and PV9-2960r-B (5'ccggatccagcgggtgtcggtgg), and PV9-3171f-B (5'cggatccgcgtcgacaatcacg) and PV9-3622r-E (5'cgcgaattcggtggcggcatgacg). The PCR products were digested with HindIII plus BamHI and BamHI plus EcoRI, respectively, and were ligated to HindIII plus EcoRI-restricted $\mathrm{pK} 18$ mobsacB. The resulting plasmids $\mathrm{pKR} \Delta 02$ and $\mathrm{pKR} \Delta 03$ were transferred into strain CIAT899 by triparental matings, and double recombinants were selected on PY medium at $\mathrm{pH}$ 6.8 amended with $12 \%$ sucrose, as previously reported (Vinuesa et al. 2003). Two nonpolar mutants, hereafter named 899-sycA $\Delta 1$ and 899-ols $C \Delta 1$, were obtained.

\section{Complementation of strain 899-ols $C \Delta 1$ with pBRR-1,6BE.}

A 1,660-bp EcoRI-BamHI fragment was amplified with primers PV9-1962f-B and PV9-3622r-E and was cloned into pBBR-MCS5 $\left(\mathrm{Gm}^{\mathrm{r}}\right)$, a broad-host range vector (Kovach et al. 1995) to obtain pBRR-1,6BE. The cloned fragment contains the whole gene encoded by olsC and an additional 534 bp upstream of the predicted start codon with the region carrying the putative promoter sequence predicted by the NNPP server (Fig. 1). This fragment was cloned in the opposite direction to the lac $Z$ promoter of the vector, in order to avoid vector- derived expression. Plasmid pBRR-1,6BE was transferred into mutant 899 -ols $C \Delta 1$ by triparental mating, and transconjugants were selected on PY and MM plates amended with Gm, Ap, and Nal. The empty pBBR-MCS5 vector was transferred into 899-olsC $\Delta 1$ as a control of the complementation, and transconjugants were selected as mentioned before.

\section{Plant tests.}

$P$. vulgaris seeds were surface-sterilized with $1.2 \%$ sodium hypochlorite and were germinated on $1 \%$ agar-water plates as described (Vinuesa et al. 1999). Seedlings were transferred to 250-ml flasks filled with vermiculite and nitrogen-free nutrient solution (Fahraeus 1957) and were inoculated with about $10^{5}$ CFU per plant. Plants were grown in a controlled growth chamber and harvested $21 \mathrm{dpi}$. Nitrogenase activity of nodulated roots was determined by acetylene reduction assay. Competition experiments were performed by coinoculating the mutant strain together with a gusA-tagged reported strain, CIAT899-G1, at a low-inoculum titer (approximately 500 cells per plantlet) to minimize nodule coinfections, as previously described (Vinuesa et al. 2003). Plants were harvested $21 \mathrm{dpi}$, and blue nodules were counted after $\beta$-glucuronidase staining (Wilson et al. 1995).

\section{In vivo labeling of rhizobial strains with $\left[{ }^{14} \mathrm{C}\right]$ acetate or $\left[{ }^{14} \mathrm{C}\right]$ ornithine and analysis of lipid extracts.}

The lipid compositions of $R$. tropici CIAT899, mutant 899ols $C \Delta 1$, and complemented mutant $899-$ ols $C \Delta 1 / \mathrm{pBBR} 1,6 \mathrm{BE}$ were determined after labeling with $\left[1-{ }^{14} \mathrm{C}\right]$ acetate $(60$ $\mathrm{mCi} / \mathrm{mmol}$; Amersham) during growth on PY medium for 24 h. The incorporation of ornithine into lipids was followed by labeling $R$. tropici CIAT899 with DL- $\left[1-{ }^{14} \mathrm{C}\right]$ ornithine (56 $\mathrm{mCi} / \mathrm{mmol}$; Amersham) during growth on MM for $48 \mathrm{~h}$. Cultures $(2 \mathrm{ml})$ were inoculated from precultures to an initial optical density at $600 \mathrm{~nm}$ of 0.05 in the respective medium. After the addition of $1 \mu \mathrm{Ci}\left[1-{ }^{14} \mathrm{C}\right]$ acetate or of $0.5 \mu \mathrm{Ci} \mathrm{DL}-[1-$ ${ }^{14} \mathrm{C}$ ]ornithine to the respective cultures, they were incubated at $28^{\circ} \mathrm{C}$ with appropriate shaking. At the end of the growth period, cells were harvested by centrifugation and resuspended in $100 \mu \mathrm{l}$ of water, and lipid extracts were obtained according to Bligh and Dyer (1959). Aliquots of the lipid extracts were spotted on high-performance TLC silica gel 60 (Merck, Poole, U.K.) plates and were separated in two dimensions using chloroform/methanol/water (140:60:10, $\mathrm{vol} / \mathrm{vol} / \mathrm{vol})$ as a mobile phase for the first dimension and chloroform/methanol/ acetic acid (130:50:20, vol/vol/vol) for the second. Primary amine-containing lipids were visualized by spraying the plates with a solution of $0.2 \%$ ninhydrin in acetone and subsequent treatment at $100^{\circ} \mathrm{C}$ for $5 \mathrm{~min}$. To quantify the membrane lipid composition, developed 2D-TLC plates were stained with iodine and the radioactivity of individual spots was quantified in a scintillation counter, as previously described (Geiger et al. 1999).

\section{ACKNOWLEDGMENTS}

We acknowledge the support of the German Science Foundation through SFB 395 (Project A6), the European Union for INCO-DEV Project (ICA4CT-2001-10057) and DGAPA-UNAM-Mexico (PAPIIT grants 200802 and 205802) for financial support.

\section{LITERATURE CITED}

Aarons, S. R., and Graham, P. H. 1991. Response of Rhizobium leguminosarum bv. phaseoli to acidity. Plant Soil 134:145-151.

Accardi, A., and Miller, C. 2004. Secondary active transport mediated by a prokaryotic homologue of $\mathrm{ClC} \mathrm{Cl}^{-}$channels. Nature 427:803-807.

Accardi, A., Kolmakova-Partensky, L., Williams, C., and Miller, C. 2004. 
Ionic currents mediated by a prokaryotic homologue of $\mathrm{CLC} \mathrm{Cl}^{-}$channels. J. Gen. Physiol. 123:109-119.

Ballen, K., Graham, P., Jones, R., and Bowers, J. 1990. Acidity and calcium interaction affecting cell envelope stability in Rhizobium. Can. J. Microbiol. 44:582-587.

Bligh, E. G., and Dyer, J. W. 1959. A rapid method of total lipid extraction and purification. Can. J. Biochem. Physiol. 37:911-917.

Chen, H., Richardson, A. E., and Rolfe, B. G. 1993a. Involvement of genes on a megaplasmid in the acid-tolerant phenotype of Rhizobium leguminosarum biovar trifolii. Appl. Environ. Microbiol. 6:1058-1064.

Chen, H., Richardson, A. E., and Rolfe, B. G. 1993b. Studies of the physiological and genetic basis of acid tolerance in Rhizobium leguminosarum biovar trifolii. Appl. Environ. Microbiol. 6:1798-1804.

Chen, T. Y. 2005. Structure and function of ClC channels. Annu. Rev. Physiol. 67:809-839.

Day, D. A., Poole, P. S., Tyerman, S. D., and Rosendahl, L. 2001. Ammonia and amino acid transport across symbiotic membranes in nitrogenfixing legume nodules. Cell. Mol. Life Sci. 58:61-71.

de Rudder, K. E. E., Thomas-Oates, J. E., and Geiger, O. 1997. Rhizobium meliloti mutants deficient in phospholipid $N$-methyltransferase still contain phosphatidylcholine. J. Bacteriol. 179:6921-6928.

Ding, Y., and Waldor, M. K. 2003. Deletion of a Vibrio cholerae ClC channel results in acid sensitivity and enhanced intestinal colonization. Infect. Immun. 71:4197-4200.

Ditta, G., Stanfiels, S., Corbin, D., and Helinski, D. 1980. Broad host range DNA cloning system from gram-negative bacteria: Construction of a gene bank of Rhizobium meliloti. Proc. Natl. Acad. Sci. U.S.A 77:7347-7351.

Dutzler, R. 2004. Structural basis for ion conduction and gating in $\mathrm{ClC}$ chloride channels. FEBS (Fed. Eur. Biochem. Soc.) Lett. 564:229-233.

Dutzler, R., Campbell, E. B., Cadene, M., Chait, B. T., and MacKinnon, R. 2002. X-ray structure of a ClC chloride channel at $3.0 \AA$ reveals the molecular basis of anion selectivity. Nature 415:287-294.

Dutzler, R., Campbell, E. B., and MacKinnon, R. 2003. Gating the selectivity filter in ClC chloride channels. Science 300:108-112.

Fahraeus, G. 1957. The infection of clover root hair by nodule bacteria studied by a single glass slide technique. J. Gen. Microbiol. 16:374 381

Figurski, D. H., and Helinski, D. R. 1979. Replication of an origin-containing derivative of plasmid RK2 dependent on a plasmid function provided in trans. Proc. Natl. Acad. Sci. U.S.A. 76:1648-1652.

Foster, J. W. 1999. When protons attack: Microbial strategies of acid adaptation. Curr. Opin. Microbiol. 2:170-174.

Gao, J. L., Weissenmayer, B., Taylor, A. M., Thomas-Oates, J., LópezLara, I. M., and Geiger, O. 2004. Identification of a gene required for the formation of lyso-ornithine lipid, an intermediate in the biosynthesis of ornithine-containing lipids. Mol. Microbiol. 53:1757-1770.

Geiger, O., Röhrs, V., Weissenmayer, B., Finan, T. M., and Thomas-Oates, J. E. 1999. The regulator gene $p h o B$ mediates phosphate stress-controlled synthesis of the membrane lipid diacylglyceryl- $N, N, N$-trimethylhomoserine in Rhizobium (Sinorhizobium) meliloti. Mol. Microbiol. 32:63-73.

Gibbons, H. S., Lin, S., Cotter, R. J., and Raetz, C. R. 2000. Oxygen requirement for the biosynthesis of the S-2-hydroxymyristate moiety in Salmonella typhimurium lipid A. Function of $\mathrm{LpxO}$, a new $\mathrm{Fe}^{2+} / \mathrm{alpha}-$ ketoglutarate-dependent dioxygenase homologue. J. Biol. Chem. 275:32940-32949.

Glenn, A. R., Reeve, W. G., Tiwari, R. P., and Dilworth, M. J. 1999. Acid tolerance in root nodule bacteria. Novart. Fdn. Symp. 221:112-126.

Graham, P. H. 1992. Stress tolerance in Rhizobium and Bradyrhizobium, and nodulation under adverse soil conditions. Can. J. Microbiol. 38:475-484.

Graham, P. H., Viteri, S. E., Mackie, F., Vargas, A. A. T., and Palacios, A 1982. Variation in acid soil tolerance among strains of Rhizobium phaseoli. Field Crop Res. 5:121-128.

Graham, P. H., Draeger, K. J., Ferrey, M. L., Conroy, M. J., Hammer, B. E., Martínez, E., Aarons, S. R., and Quinto, C. 1994. Acid pH tolerance in strains of Rhizobium and Bradyrhizobium, and initial studies on the basis for acid tolerance of Rhizobium tropici UMR1899. Can. J. Microbiol. 40:189-207.

Hungria, M., and Vargas, M. 2000. Environmental factors affecting $\mathrm{N}_{2}$ fixation in grain legumes in the tropics, with an emphasis on Brazil. Field Crop Res. 65:151-164.

Iyer, R., Iverson, T. M., Accardi, A., and Miller, C. 2002. A biological role for prokaryotic $\mathrm{ClC}$ chloride channels. Nature 419:715-718.

Jia, S., McGinnis, K., VanDusen, W. J., Burke, C. J., Kuo, A., Griffin, P. R., Sardana, M. K., Elliston, K. O., Stern, A. M., and Friedman, P. A. 1994. A fully active catalytic domain of bovine aspartyl (asparaginyl) beta-hydroxylase expressed in Escherichia coli: Characterization and evidence for the identification of an active-site region in vertebrate alpha-ketoglutarate-dependent dioxygenases. Proc. Natl. Acad. Sci. U.S.A. 91:7227-7231.

Jjemba, P. K. 2001. The interaction of protozoa with their potential prey bacteria in the rhizosphere. J. Eukaryot. Microbiol. 48:320-324.

Kingsley, M. T., and Bohlool, B. 1992. Extracellular polysaccharide is not responsible for aluminum tolerance of Rhizobium leguminosarum by. phaseoli CIAT899. Appl. Environ. Microbiol. 58:1095-1101.

Kovach, M. E., Elzer, P. H., Hill, D. S., Robertson, G. T., Farris, M. A., Roop, R. M., 2nd, and Peterson, K. M. 1995. Four new derivatives of the broad-host-range cloning vector pBBR1MCS, carrying different antibiotic-resistance cassettes. Gene 166:175-176.

Lodwig, E., Hosie, A., Bourdes, A., Findlay, K., Allaway, D., Karunakaran, R., Downie, J., and Poole, P. S. 2003. Amino-acid cycling drives nitrogen fixation in the legume-Rhizobium symbiosis. Nature 422:722-726.

López-Lara, I. M., Sohlenkamp, C., and Geiger, O. 2003. Membrane lipids in plant-associated bacteria: Their biosyntheses and possible functions. Mol. Plant-Microbe Interact. 16:567-579.

Marschner, H. 1995. Mineral Nutrition of Higher Plants. Academic Press, London.

Martínez-Romero, E., Segovia, L., Mercante, F. M., Franco, A. A., Graham, P., and Pardo, M. A. 1991. Rhizobium tropici, a novel species nodulating Phaseolus vulgaris L. beans and Leucaena sp. trees. Int. J. Syst. Bacteriol. 41:417-26.

Merrell, D. S., and Camilli, A. 2002. Acid tolerance of gastrointestinal pathogens. Curr. Opin. Microbiol. 5:51-55.

Minder, A. C., de Rudder, K. E., Narberhaus, F., Fischer, H. M., Hennecke, H., and Geiger, O. 2001. Phosphatidylcholine levels in Bradyrhizobium japonicum membranes are critical for an efficient symbiosis with the soybean host plant. Mol. Microbiol. 39:1186-1198.

Munns, D., Hohenberg, T., Righetti, T., and Lauter, D. 1981. Soil acidity of symbiotic and nitrogen-fertilized soybeans. Agron. J. 73:407-410.

Munns, D., Keyser, H., Fogle, V., Hohenberg, J., Righetti, T., Lauter, D., Zaroug, M., Clarkin, K., and Whitacre, K. 1979. Tolerance of soil acidity in symbioses of mung bean with rhizobia. Agron. J. 71:256-260.

Noel, K. D., Sánchez, A., Fernández, L., Leemans, J., and Cevallos, M. A 1984. Rhizobium phaseoli symbiotic mutants with transposon Tn5 insertions. J. Bacteriol. 158:148-155.

Nogales, J., Campos, R., BenAbdelkhalek, H., Olivares, J., Lluch, C., and Sanjuan, J. 2002. Rhizobium tropici genes involved in free-living salt tolerance are required for the establishment of efficient nitrogen-fixing symbiosis with Phaseolus vulgaris. Mol. Plant-Microbe Interact. 15:225-232.

O'Hara, G. W., and Glenn, A. R. 1994. The adaptive acid tolerance response in root nodule bacteria and Escherichia coli. Arch. Microbiol. 161:286-292.

Peick, B., Graumann, P., Schmid, R., Marahhiel, M., and Werner, D. 1999. Differential $\mathrm{pH}$-induced proteins in Rhizobium tropici CIAT899 and Rhizobium etli CIAT611. Soil Biol. Biochem. 31:189-194.

Reeve, W. G., Dilworth, M. J., Tiwari, R. P., and Glenn, A. R. 1997. Regulation of exopolysaccharide production in Rhizobium leguminosarum biovar viciae WSM710 involves exoR. Microbiology 143:1951-1958.

Riccillo, P. M., Muglia, C. I., de Bruijn, F. J., Roe, A. J., Booth, I. R., and Aguilar, O. M. 2000. Glutathione is involved in environmental stress responses in Rhizobium tropici, including acid tolerance. J. Bacteriol. 182:1748-1753.

Sambrook, J., Fritsch, E. F., and Maniatis, T. 1989. Molecular Cloning: A Laboratory Manual. Cold Spring Harbor Laboratory Press, Cold Spring Harbor, NY, U.S.A.

Schäfer, A., Tauch, A., Jäger, W., Kalinowski, G., Thierbach, G., and Pühler, A. 1994. Small mobilizable multi-purpose cloning vectors derived from the Escherichia coli plasmids pK18 and pK19: Selection of defined deletions in the chromosome of Corynebacterium glutamicum. Gene 145:69-73

Simon, R., Priefer, U., and Pühler, A. 1983. A broad host range mobilization system for in vivo genetic engineering: Transposon mutagenesis in gram-negative bacteria. Bio/Technology 1:784-791.

Sohlenkamp, C., López-Lara, I. M., and Geiger, O. 2003. Biosynthesis of phosphatidylcholine in bacteria. Prog. Lipid Res. 42:115-162.

Taylor, C. J., Anderson, A. J., and Wilkinson, S. G. 1998. Phenotypic variation of lipid composition in Burkholderia cepacia: A response to increased growth temperature is a greater content of 2-hydroxy acids in phosphatidylethanolamine and ornithine amide lipid. Microbiology 144:1737-1745.

Udvardi, M. K., and Day, D. A. 1997. Metabolite transport across symbiotic membranes of legume nodules. Annu. Rev. Plant Physiol. Plant Mol. Biol. 48:493-523

Vargas, C., Martínez, J. L., Megías, M., and Quinto, C. 1990. Identification and cloning of nodulation genes and host specificity determinants of the broad host-range Rhizobium leguminosarum biovar phaseoli strain CIAT899. Mol. Microbiol. 11:1899-1910. 
Vinuesa, P., Reuhs, B. L., Breton, C., and Werner, D. 1999. Identification of a plasmid-borne locus in Rhizobium etli KIM5s involved in lipopolysaccharide O-chain biosynthesis and nodulation of Phaseolus vulgaris. J. Bacteriol. 181:5606-5614.

Vinuesa, P., Neumann-Silkow, F., Pacios-Bras, C., Spaink, H. P., MartínezRomero, E., and Werner, D. 2003. Genetic analysis of a pH-regulated operon from Rhizobium tropici CIAT899 involved in acid tolerance and nodulation competitiveness. Mol. Plant-Microbe Interact. 16:159-168.

Walker, T. S., Bais, H. P., Grotewold, E., and Vivanco, J. M. 2003. Root exudation and rhizosphere biology. Plant Physiol. 132: 44-51.

Weisburg, W. G., Barns, S. M., Pelletier, D. A., and Lane, D. J. 1991. 16S ribosomal DNA amplification for phylogenetic study. J. Bacteriol. 173:697-703.

Weissenmayer, B., Gao, J. L., López-Lara, I. M., and Geiger, O. 2002. Identification of a gene required for the biosynthesis of ornithinederived lipids. Mol. Microbiol. 45:721-733.

Werner, D., Wilcockson, J., and Zimmermann, E. 1975. Adsorption and selection of rhizobia with ion-exchange papers. Arch. Microbiol. 105:27-32.
Wilson, K. J., Sessitsch, A., Corbo, J. C., Giller, K. E., Akkermans, A. D and Jefferson, R. A. 1995. Beta-Glucuronidase (GUS) transposons for ecological and genetic studies of rhizobia and other gram-negative bacteria. Microbiology 141:1691-1705.

Zahran, H. H. 1999. Rhizobium-legume symbiosis and nitrogen fixation under severe conditions and in an arid climate. Microbiol. Mol. Biol. Rev. 63:968-989.

Zhu, X., and Williamson, P. R. 2003. A CLC-type chloride channel gene is required for laccase activity and virulence in Cryptococcus neoformans. Mol. Microbiol. 50:1271-1281.

\section{AUTHOR-RECOMMENDED INTERNET RESOURCES}

Genopole's FrameD gene finder program: genopole.toulouse.inra.fr/bioinfo/FrameD/FD

The Berkeley Drosophila Genome Project NNPP server: www.fruitfly.org/seq_tools/promoter.html 